\title{
Anunciando a desgraça: o conceito de áte e o coro na tragédia de Ésquilo
}

Announcing misfortune: the concept of $\ddot{\alpha} \tau \eta$ and the chorus in the tragedy of Aeschylus

Marco Aurélio Rodrigues

Universidade Federal do Amapá, Brasil

marcoaurelio@unifap.br

(D) http://orcid.org/0000-0001-6104-227X

\section{Resumo:}

O coro na tragédia grega sempre foi considerado um importante elemento da composição dramática. Mais do que isso, principalmente no período esquiliano, era uma das partes essenciais da representação, manifestando-se como a própria voz do povo que se revelava e inqueria as personagens sobre os acontecimentos, as informações e as situações que aconteciam diante dele. Em Ésquilo, particularmente, o coro cumpre um curioso papel, pois é também o responsável por citar, na maior parte das ocorrências de todas as tragédias remanescentes do autor, o conceito de $\alpha ँ \tau \eta$, cuja definição compreende desde uma mera turvação das ideias até mesmo a própria desgraça consumada. Assim, o presente artigo, apoiado, sobretudo, pelas ideias propostas por Doyle (1984), analisa algumas passagens em que tal fato ocorre e, para além disso, os possíveis movimentos que fazem uma noção complexa do pensamento grego aparecer com maior frequência justamente nas partes líricas das tragédias.

Palavras-chave: Ésquilo, Tragédia, Coro, $\ddot{\alpha} \tau \eta$.

\section{ABstRACT:}

The chorus in Greek tragedy has always been considered an important element of dramatic composition. Also, especially in the esquilian period, it was one of the essential parts of the representation, manifesting itself as the voice of the people who revealed and inquired the characters about the events, the information and the situations that happened before him. In Aeschylus, particularly, the chorus plays a curious role, as it is also responsible for citing, in most instances of all the author's remaining tragedies, the concept of $\ddot{\alpha} \tau \eta$, whose definition ranges from a mere clouding of ideas to even the consummate misfortune itself. Thus, the present paper, supported above all by the ideas proposed by Doyle (1984), analyzes some passages in which this fact occurs and, in addition, the possible movements that make a complex notion of Greek thought appear more often in the lyrical parts of tragedies.

KEYwORDS: Aeschylus, Tragedy, Chorus, $\ddot{\alpha} \tau \eta$.

\section{INTRODUÇÃo}

A tragédia e a comédia tornaram-se, ao longo do século $\mathrm{V}$, o centro do debate de questões próprias da cidade democrática grega. Dentro de um formato sofisticado e composto por elementos que se tornariam clássicos no teatro, como a presença do coro e a introdução cada vez mais elaborada das personagens e suas relações em cena, o uso do tema mítico, a par do tema "histórico", inspirado na realidade imediata, tornavase o veículo condutor para os poetas exporem também uma nova forma de pensamento.

Tratava-se de um novo período na história de toda a Grécia e é preciso entender em que medida o drama trágico vem para se aliar a essa nova sociedade. Relativamente a isso, disserta Vernant (2008, p. 04):

O momento da tragédia é, pois, aquele em que se abre, no coração da experiência social, uma distância bastante grande para que, entre o pensamento jurídico e social de um lado e as tradições míticas e heroicas de outro, as oposições se delineiem claramente; bastante curta, entretanto, para que os conflitos de valor sejam ainda dolorosamente sentidos e para que o confronto não deixe de efetuar-se.

Esse embate, no entanto, entre um pensamento da cidade e a tradição oral e familiar, é combinado de forma magistral pelos tragediógrafos gregos. De certo modo, há uma nova forma de se encarar a realidade e questioná-la, por outro lado, as histórias passadas de geração em geração reforçam a tradição, quando utilizadas como motivo para o desenvolvimento do drama. Assim, mesclar os relatos tradicionais com as novas

Recepción: 01 de mayo de 2020 | Aceptación: 26 de mayo de 2020 | Publicación: 12 de junio de 2020

Cita sugerida: Rodrigues, M. A. (2020). Anunciando a desgraça: o conceito de áte e o coro na tragédia de Ésquilo. Synthesis, 27(1), e071. https://doi.org/10.24215/1851779Xe071 
ideias e reflexões da cidade só reforçaria, no palco, a evolução deste $\pi 0 \lambda i \tau \eta$ s. Não obstante, não é tarefa fácil lidar com temas conhecidos e que, seguindo apenas o costume, poderiam soar enfadonhos. É por isso que não é unicamente por uma herança arqueológica que a tríade trágica é formada por Ésquilo, Sófocles e Eurípides. Analisados individualmente, cada qual serviu à tragédia de forma peculiar, inserindo no mito os elementos necessários para atrair o público e atingir o sentimento de tensão e exaltação, marcando etapas relevantes no desenvolvimento da história e do gênero trágico.

Assim, a trama desenvolvida pelo autor acaba por explorar diferentes aspectos dos mitos. Vidal-Naquet (2008) discorre que, na tragédia, "é preciso que a cidade ao mesmo tempo se reconheça e se questione" (p. 233), e é justamente isso que ocorre quando os autores apresentam as narrativas das famílias dos Labdácidas e dos Atridas, além de parte do Ciclo Troiano referente aos Priamidas. Para além da riqueza do material mítico, as histórias dispunham de uma vantagem crucial: todo grego conhecia, pelo menos em partes, as vidas daquelas personagens representadas no teatro e entendia claramente as inovações e indagações propostas por Ésquilo, Sófocles e Eurípides.

Toda essa evolução cultural tem sido motivo, dentre os estudiosos contemporâneos, de inúmeras e oportunas reflexões. ${ }^{1}$ Sendo assim, dentro dos debates promovidos pelo mito na tragédia, expressões do pensamento grego foram comumente discutidas, como o conceito de $\ddot{\alpha} \tau \eta$, que, curiosamente, mereceu atenção especial no século XX. Seu cuidado deve-se ao fato de a palavra, que aparece na literatura grega, pela primeira vez, em Homero, tanto na Ilíada como na Odisseia, ter uma recorrência frequente dentro da tragédia, ${ }^{2}$ deixando pouco a pouco de ser usada na literatura posterior. Por isso, é sempre prudente recordar a frase de Doyle (1984) “qualquer estudo sobre à $َ \eta$ deve ter a tragédia grega como seu núcleo” (p. 01). ${ }^{3}$

No universo que compreende a tragédia clássica, o termo passa por uma expansão de significado. É perceptível que o conceito de $\alpha َ \eta \eta$ deixa de possuir a mesma relevância de Ésquilo a Eurípides. Segundo Saïd (1976), após a tragédia, o termo assume um sentido ainda mais enfraquecido e passa a designar "um temor próprio do homem supersticioso" (p. 76). Esse fato ganha maior vigor no drama euripidiano, cujo pensamento recebe contornos racionais mais evidentes e influenciados pela contemporaneidade da reflexão socrática. A noção de à $\tau \eta$, exposta por Ésquilo, torna-se muito próxima à apresentada por Homero e Hesíodo, com apenas uma importante ressalva de Dodds (1963), para o qual o termo deixa de significar apenas um "estado de espírito" (p. 38), para ser aplicado também aos desastres decorrentes da ação da å̃ $\eta$ sobre o homem.

Portanto, é possível perceber como os autores lidarão com o mito dentro da tragédia. A arte de cada um deles será explorada em toda sua magnitude, porém, sem esquecerem da tradição política, social e religiosa, bem como das novas ideias e reflexões pelas quais aquele universo transitava. Todos esses movimentos possibilitam leituras plurais e, mais do que isso, permite que as preocupações do período possam ser inseridas dentro do discurso do drama para a identificação direta do espectador em diálogo com os antepassados gloriosos. Nesse sentido, há que se recordar ainda, o efeito causado pelos cantos corais que, em muitos momentos, retomam questões pertinentes ao mito como forma de rememorar a audiência e, é claro, sublinhar informações que sejam oportunas ao drama. É o caso, por exemplo, do coro de anciãos de Maratona em Heráclidas (vv. 232-235), em que o canto coral se compadece da aflição de Iolau e dos filhos de Héracles, lembrando a linhagem das crianças e a heroicidade do pai. Além de um resgate do passado fica evidente, também, o impacto que o drama instaurava na sociedade, até mesmo perpetuando imagens construídas no ambiente do teatro.

\section{O MiTO DA ÁTE}

Antes de começar a pensar propriamente no conceito de ä $\tau \eta$ e as implicações existentes nesse complexo vocábulo, é necessário entender em que momento da narrativa mítica ele se insere. É possível, logo pela análise do mito, já entender o porquê de o termo estar sempre ligado a questões malignas ou que remetam a uma 
punição ao homem. Moreau (1986) denomina como "demônios infernais" (p. 152) àqueles presentes na obra de Ésquilo que propagam a violência e a desordem no mundo dos homens. Dentre estes demônios, encontra-

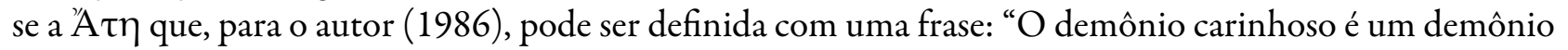
maléfico" (p. 158). A frase do helenista contém em seu significado uma gama de explicações pertinentes ao funcionamento do conceito de $\alpha \dot{\tau} \eta$ na tragédia grega. É possível perceber o motivo pelo qual o vocábulo passeia de forma tão ampla dentro do curto espaço de tempo que o drama trágico foi produzido na Grécia antiga. Para um teatro que luta entre dois polos, o de mobilizar e de intrigar seu espectador, nada mais normal que, constantemente, as personagens envoltas em conflitos tenham na $\alpha ँ \tau \eta$ a justificativa ou os argumentos que os impeçam de cometer erros. Sendo assim, Grimal (1993, p. XXXV) ressalta a dificuldade em se alcançar para os mitos uma única via de explicação coerente, que não esbarre em algum momento em conflito com outras versões. Assim assevera o autor:

A mitologia helénica resulta da acção de influências ainda mais diversas, entre as quais o papel dos elementos indo-europeus parece bastante limitado. Foi em todo o caso recoberto por contribuições decisivas oriundas do mundo semita e, mais vagamente, dessas civilizações "mediterrâneas" de que começamos a ver os estratos sucessivos nessa encruzilhada que foi sempre o Mediterrâneo oriental. Nesta espantosa síntese, é difícil discernir a parte que pertence a cada um. As lendas formamse, evoluem, tornam-se matéria literária ou "histórica", mudam de caráter à medida que os centros de difusão se deslocam de ilha em ilha, de continente em continente, passando da Síria para Creta, de Rodes para Micenas, de Mileto para Atenas. Não é de estranhar que, nestas condições, se assista a uma fusão de tradições, de contos, de mitos, cada um referente a um episódio ou a um momento, e misturando-se todos na confusão total.

Dessa forma, o que fica evidente nos manuais de mitologia é que os mitos expostos são uma síntese das versões mais recorrentes ao longo da tradição. Mesmo se considerarmos a questão da livre criação poética dos autores, o fato de existirem outras variantes ratifica a escolha quando da elaboração do drama. Deste modo, Grimal (1993, p. 52) apresenta, no verbete referente à ä $\tau \eta$, a seguinte versão para o mito:

Personificação do Erro. Divindade leve e ágil, seus pés só poisam sobre a cabeça dos mortais, sem que eles se apercebam. Aquando do juramento de Zeus, em que este se comprometeu a dar a supremacia ao "primeiro descendente de Perseu que ia nascer" e submeteu desse modo Héracles a Euristeu, foi Átē quem o enganou. Zeus vingou-se, precipitando-a do Olimpo. Átē caiu na Frígia, sobre uma colina que recebeu o nome de Colina do Erro. Foi ali que Ilo construiu a cidadela de Ílion (Tróia). Zeus, precipitando Átē do alto do céu, cortou-lhe para sempre a possibilidade de residir no Olimpo. É por isso que o Erro constitui a triste partilha da humanidade.

Homero, no Canto XIX da Ilíada (XIX.85-138), faz uma detalhada narrativa dos acontecimentos que antecedem o nascimento de Héracles e a influência que a deusa 'A $\tau \eta$ teve no seu destino, motivando seu desterro. É, dessa forma, Homero o primeiro a apresentar aos gregos ou, pelo menos, a registrar os motivos que levaram a deusa 'A $\mathrm{\tau} \eta$ a se instalar entre os homens. Fica evidente que o poder da deusa não mede vítimas, desrespeitando até mesmo o pai dos deuses, visto que sua única finalidade é causar a confusão mental em seu escolhido. Hesíodo, por sua vez, sendo um dos primeiros a teorizar sobre a Cosmogonia grega, relata o nascimento da deusa 'Atๆ, justificando a que família ela pertence e, portanto, confirmando sua origem obscura. Para Roisman (1983), “A inovação de Hesíodo não está na percepção da átē mas em sua função e

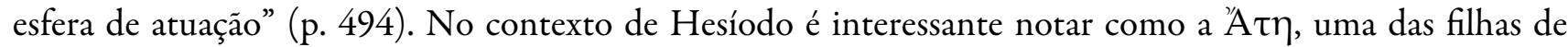
$\mathrm{N} i \xi$, "Noite”, une-se a outras divindades, todas com aspectos negativos. Sendo assim, a partir de Hesíodo, uma nova face da deusa vai se delimitando e, mesclando-a com a noção apresentada por Homero, chegamos ao conceito vigente na tragédia.

O conceito de $\ddot{\alpha} \tau \eta$, assim sendo, por sua natureza primitiva, estabelece dentro do mito uma relação, ora de influência, ora de ação concreta e física na vida do grego. No entanto, a relação entre o significado e a ação torna-se intrínseca e, por diversos momentos, o conceito vocabular confunde-se com a figuração do divino, como se efeito e causa não possuíssem uma relação de completa distinção. 


\section{O CORO E A ÁTE}

Em um trabalho dedicado à recepção de Ésquilo, Ewans (2018, p. 205) acrescenta a relevância que o coro tem dentro das peças do dramaturgo, fato este que explicaria uma dificuldade nas adaptações para a ópera, porque não agradava ao público barroco a complexidade, a linguagem exagerada e obscura, além de uma ausência de elementos de aventura que faziam com que Ésquilo elevasse o coro a um patamar mais dileto do que seus sucessores.

A reflexão de Ewans é pertinente quando se reflete sobre a estrutura da obra de Ésquilo. Curiosamente, quatro das sete tragédias do autor que chegaram até nós, apontam, através dos títulos, Persas, Suplicantes, Coéforas e Eumênides, para a pertinência do papel do coro. A esse respeito, por exemplo, vale ressaltar a questão abordada por Kitto (2011), sobre a tragédia Suplicantes, que o autor classifica como uma "tragédia lírica” (p. 01), tal a predominância da função do coro.

O coro na tragédia que, segundo Dale (1969, p. 211), personifica uma coletividade anônima, é responsável por uma contribuição emocional de grande importância e, portanto, enfatizar a existência da ä $\tau \eta$ em passos líricos é reconhecer o grau de carga afetiva que o conceito pretende transmitir. A esse respeito, Ley (2007) reforça, por exemplo, que mesmo com uma estrutura bem diferente, o coro de Persas (472 a.C.) e o coro de Bacantes ( 405 a.C.) ainda assim sustentam uma função primordial: "uma ideia emocional”(p. 139). Dessa forma, a emoção é a ênfase que o conceito de å $\tau$ recebe dentro da tragédia e, seu uso, também representa a crescente tensão que o coro propõe ao espectador, como pontua Vickers (1973, p. 128), nem sempre por meio de um questionamento moral, mas por salientar os grandes dilemas.

Tal aspecto explica o porquê de um conceito tão claro e pontuado nas obras homéricas ainda possuir importância na tragédia clássica, mesmo revestido de uma nova abordagem. Sendo assim, não apenas a palavra, singular ou plural, auxilia na interpretação do sentido que o conceito representa em qualquer passo analisado, mas o contexto torna-se de extrema importância para se conceituar a $\ddot{\alpha} \tau \eta$ dentro de um universo estabelecido pelo autor. Portanto, há no quesito estrutural da tragédia elementos que não podem deixar de ser comentados. É preciso, assim, levar em consideração que das 118 ocorrências de $\alpha َ \tau \eta$ em toda a tragédia grega, 84 delas estão em passagens líricas; apenas 34 aparecem por meio da fala de personagens que não seja o coro; das passagens líricas, 27 estão no autor em questão, ${ }^{4}$ sendo que há 48 incidências nas sete tragédias remanescentes do eleusino.

A presença, assim, é relevante para se entender a importância do coro dentro da tragédia de Ésquilo. No entanto, algumas passagens tornam-se mais significativas que outras. Dessa forma, pela extensão das análises, o presente artigo propõe-se a demonstrar mais especificamente, algumas passagens que enfatizam a potência dramática do coro.

Vale ressaltar, como reforça Swift (2010, p. 37) que o coro, por estar presente no cotidiano da população grega tinha papel em várias funções da organização social, cultural e religiosa da cidade, porém, o coro de uma montagem trágica era mais seletivo e exigia várias habilidades dos componentes, o que se tornaria uma verdadeira arte na esfera cultura da cidade. Não é para menos que o personagem Ateniense, no diálogo Leis, de

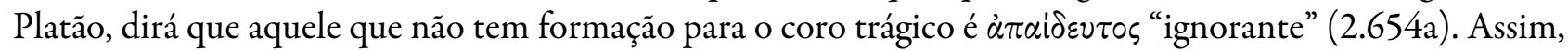
observar o conceito de $\alpha \dot{\tau} \eta \eta$ por meio do coro é observar a própria voz de uma população estimulada pela arte, crítica e consciente de seu próprio tempo e história.

A fim de não alongar as discussões referentes aos mais diversos autores acerca de trechos delicados das edições das tragédias de Ésquilo, este trabalho opta pelo uso da edição de Page (1972), que vai ao encontro das análises realizadas pelos principais especialistas. Vale ressaltar que a edição escolhida tem sido acompanhada por grande parte da comunidade acadêmica. Sendo assim, a primeira aparição do conceito a que esse trabalho faz menção, por meio do coro, acontece em Persas, logo no párodo, quando o coro de anciãos apresenta a divindade e a forma como ela se comporta diante dos mortais (vv. 93-100): 


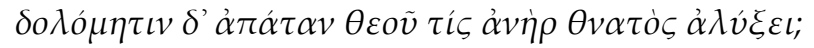

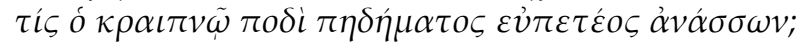

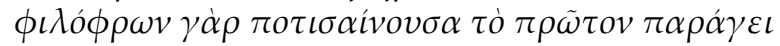

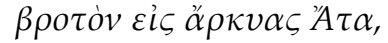

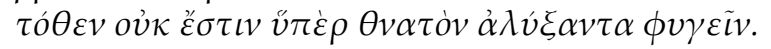

Ao dolo fraudulento da divindade que homem mortal escapará? Que chefe de rápido pé no salto cai bem? Pois amistosa, direcionando ao erro primeiramente a Obcecação acolhe um mortal em sua rede; dai em diante, não há como um mortal tendo escapado fugir.

O coro questiona justamente o fato de um ser humano ter um salto que ultrapassaria o "dolo", uma alusão à queda do homem que governa, que ocupa uma posição superior e, portanto, que teria como impacto a desonra, que é maior e mais grave do que a do simples mortal. Nota-se, assim, a preocupação do coro em relação à queda de Xerxes, foco da atenção dos anciãos e vítima da influência da à $َ \eta$. O conceito de 'A $\tau \eta$, no passo em letra maiúscula, refere-se à entidade divina, a deusa que "obceca" o homem e o deixa em um estado de "turvação do pensamento", o que significa dizer que o homem deixa de visualizar o mundo em uma perspectiva maior, podendo avaliar as consequências de seus atos e acaba agindo por impulso ou mesmo por força de uma outra potência maligna que também o esteja enredando.

Por enfocar justamente uma batalha ocorrida no mar, com imagens fortes relacionadas a questões marítimas, é possível entender um aspecto da tradição que relaciona a violência do mar com a incapacidade humana, a inconstância das ondas e a própria imensidão oculta entre as águas em um domínio que escapa ao homem. Assim sendo, $\ddot{\alpha} \tau \eta$ apresenta-se como uma pescadora, predadora da alma humana, traço estilístico que amplifica a reflexão sobre uma potência que se molda de acordo com as situações para interagir com os mortais. O vocábulo äpкus "rede" (v. 98) empenha o papel de aliar uma imagem marítima ao conceito de $\ddot{\alpha} \tau \eta$, pois, entre seus significados, Liddell e Scott (1996, p. 242) justamente pontuam um sentido relacionado à rede de caça ou utilizada na prática da pesca. Por outro lado, se o homem está sendo enredado,

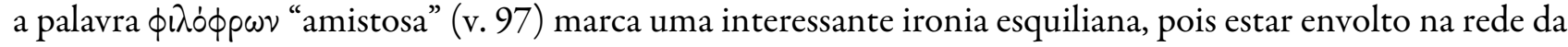
'A $\tau$ pressupõe que o homem esteja em uma situação ruinosa. No entanto, é preciso levar em consideração

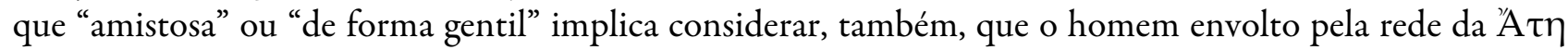
só se dá conta de sua "obcecação" quando todos os malefícios que a influência maligna pode ocasionar em sua vida já se realizaram. Por sua vez, $\phi \imath \lambda o ́ \phi \rho \omega \nu$ pode também aludir a uma outra imagem, principalmente se aliada ao verbo ¿̇ $\nu \alpha i \sigma \sigma \omega$ "saltar”, pois, como afirma Moreau (1986, p. 73), Ésquilo parece aproximar 'A $\tau \eta$ da figura de uma "cadela", fazendo referência a uma entidade traiçoeira, que atrai o homem de forma ingênua e dócil para, por fim, "abocanhá-lo". Destarte, ao pensar na imagem de uma cadela, o sentido de "obcecação" para $\ddot{\alpha} \tau \eta$ torna-se ainda mais potente, visto que o homem acaba por ser seduzido por tal deidade.

Assim sendo, negar o justo equilíbrio entre a condição humana e os deuses é incorrer em erro e, portanto, ser passível de uma punição; por isso a deusa 'Atๆ, errante entre os homens, na espreita da falha humana, acabaria por punir Xerxes e essa advertência, colocada na voz do coro, ecoa uma tradição de advertência e comedimento que, posteriormente, com Sete contra Tebas, delineia-se como uma marca da expressão moral do cidadão ateniense.

Sete Contra Tebas, apresentada em 467 a.C. ${ }^{5}$ e ganhadora do primeiro prêmio do festival, apresenta o ataque de Polinices contra Tebas e em oposição ao próprio irmão Etéocles, detentor do governo da cidade. Sete contra Tebas é a única tragédia de Ésquilo completa remanescente de uma tetralogia composta de Laio, Édipo e o drama satírico Esfinge, em que ocupava o terceiro lugar no conjunto.

Das ocorrências, duas em particular chamam a atenção justamente pela continuidade de uma expressão de censura assumida pelo coro. Assim, as mulheres tebanas, ao ouvirem de Etéocles que ele irá cumprir seu destino ao lutar contra seu próprio irmão, questionam a postura do governante (vv. 686-688): 


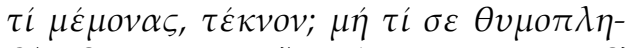

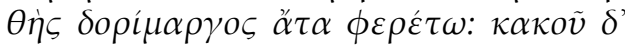

$\ddot{\varepsilon} \kappa \beta \alpha \lambda^{\prime} \ddot{\varepsilon} \rho \omega \tau O \varsigma \dot{\alpha} \rho \chi \alpha \dot{v}$.

Que desejo alimentas, filho? Näo permitas que

uma maldição assassina, cheia de fúria, te tome: essa má

paixão rejeita-a desde a sua origem.

Há na passagem uma clara referência à concretização da maldição de Édipo e, dessa forma, a tradução de $\ddot{\alpha} \tau \eta$ no passo remete à danação transmitida aos filhos. Neste caso, porém, ao mesmo tempo em que ä $\tau \eta$ é “maldição", ela também é, na perspectiva do coro, o "engano" de Etéocles, uma espécie de "perturbação" que o coloca diante de uma clássica fusão esquiliana: do destino inerente ao homem com a própria responsabilidade, fruto de decisões pessoais.

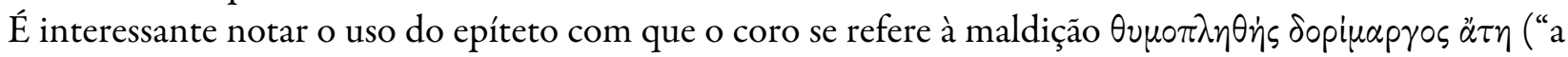
maldição assassina, cheia de fúria”, v. 687), o que possibilita múltiplas interpretações, pois demonstram a dimensão do alcance de $\alpha \dot{\tau} \tau$. Ao mesmo tempo em que possa ser a própria personificação do irmão no campo de batalha à espera de atingir seu adversário, a ä $\eta$ se configura também como a "obcecação" de Etéocles em

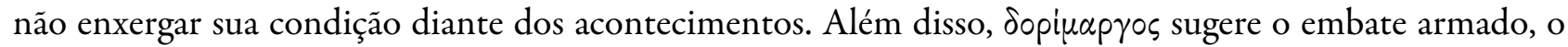
confronto das lanças que iguala os dois irmãos em uma mesma maldição, uma mesma perturbação, a mesma $\ddot{\alpha} \tau \eta$ que unifica toda a família.

Há que se ressaltar, no entanto, que a opinião do coro de mulheres tebanas, temerosas em relação à guerra, contribui para uma imagem de Etéocles como um herói perturbado, que não hesitará diante do fratricídio. Porém, ao longo da tragédia, inúmeros indícios são dados para que se apreenda de Etéocles uma imagem de sabedoria e lucidez. Trata-se de um herói que compreende seu destino, pois pertence à raça de Édipo, ao mesmo tempo em que precisa administrar a situação bélica, pois é o governante da cidade. Os versos 689-691 apontam justamente para essa consciência do herói diante da fatalidade: "toda a raça de Laio é odiada por Febo". Esta questão da maldição da raça é tratada com veemência por Thalmann (1978, p. 140),

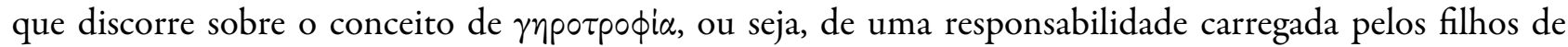
alimentarem e protegerem os pais na velhice. Destarte, Etéocles é aquele que reconhece na maldição sua parcela de compromisso com o que é herdado por ele e pelo irmão através da família de Laio. Quando o coro fala em हैk $\beta \alpha \lambda \varepsilon \dot{\alpha} \rho \chi \dot{\alpha} \nu$ (“rejeita a origem”, v. 688), está nitidamente fazendo alusão aos primórdios, à origem de todo mal entre os Labdácidas, fruto dos atos dos familiares que remontam a um passado anterior a Laio e, portanto, ao kakós ("mal", v. 687) que gerou a disputa entre os dois irmãos, ou seja, a "maldição". Aos olhos do coro de mulheres tebanas, rejeitar a maldição desde a origem é, nesta nova fase do destino que Tebas agora vive, não enfrentar o irmão na sétima porta da cidade de Tebas.

Em concordância com o último passo, as mulheres tebanas continuam a censuras as ações e, em uma referência ao resultado da ação dos dois irmãos que acabam por morrer no campo de batalha, concluem (vv. 954-956):

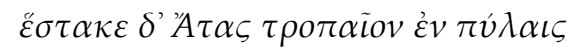

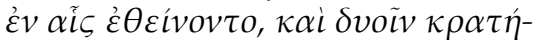

$\sigma \alpha \varsigma \dot{\varepsilon} \lambda \eta \xi \varepsilon \delta \alpha i \mu \omega v$.

Ergue-se o troféu da Maldição nas portas

em que foram abatidos, e os dois tendo

dominado, a divindade cessou.

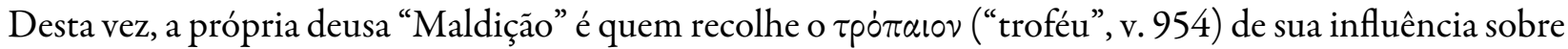
o homem, ou seja, a marca de sua conquista, de sua ação sobre a vida humana é justamente a concretização das imprecações do pai sobre os filhos. É interessante notar como a divindade 'Ã $\rceil$ é responsabilizada pelo 
fim desastroso da disputa entre os dois irmãos, ao mesmo tempo em que era o próprio motivo que os levaria àquele fim.

Se o coro de mulheres tebanas se opõe a Etéocles ao longo de toda a tragédia, é porque não possui a consciência que o próprio herói tem de sua família e da maldição dos Labdácidas. Neste ponto, Thalmann (1978, p. 141) corrobora a opinião de Cameron (1971, p. 56), pois ambos explicitam que a tragédia aponta para o ápice da maldição, a terceira geração (vv. 744-755, 812-813) que encerra a desgraça familiar. Tal aspecto foca o sentido da desgraça no papel que cabe aos irmãos, enquanto homens da linhagem de Laio, na cidade de Tebas.

A imagem construída por Ésquilo, no passo de Sete contra Tebas, de uma deusa triunfante diante de seu prêmio, é extremamente expressiva. Doyle (1984, p. 54) ressalta o fato de o mensageiro citar a $\Lambda \alpha$ ïov $\delta v \sigma \beta ం v \lambda i \alpha$ (“insensatez de Laio", v. 802), reforçando que o troféu, ou seja, os dois irmãos mortos pelo embate, nada mais é que o reflexo da imprudência de Laio, a ruína de Édipo, a perturbação de Polinices e a fúria de Etéocles. Mas fica claro também que o coro não consegue compreender a desgraça como o fim de uma maldição. A morte dos dois irmãos, para as mulheres, não é a concretização de algo que já estava previsto há muito, mas apenas o resultado de uma imponderação que seria possível e necessário evitar.

Suplicantes, apresentada por volta do ano de 463 a.C., ${ }^{6}$ dá continuidade a uma função admoestativa do coro, no entanto, com um coro formado por mulheres, as Danaides, a peça é uma verdadeira ode e exaltação à figura de Zeus, ao qual as Suplicantes invocam na busca de auxílio e amparo. Mesmo que os deuses pátrios

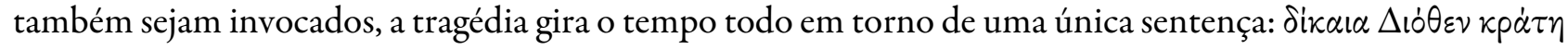
(“Justos são os poderes enviados por Zeus", v. 437). Logo nos primeiros versos da tragédia, uma passagem corrompida e muito debatida pelos estudiosos apresenta o conceito de $\ddot{\alpha} \tau \eta$. Trata-se de uma fala do coro que, segundo Doyle (1984, p. 55), apresenta questões textuais que precisam ser analisadas com cuidado. Por outro lado, a riqueza de elementos que se pode extrair de tal passagem e as conexóes estabelecidas com o conceito remetem a toda uma tradição de uso do termo.

A antístrofe em questão pertence a uma fala do coro das filhas de Dânao, em que elas potencializam de forma negativa a ação dos filhos de Egito (vv. 104-111):

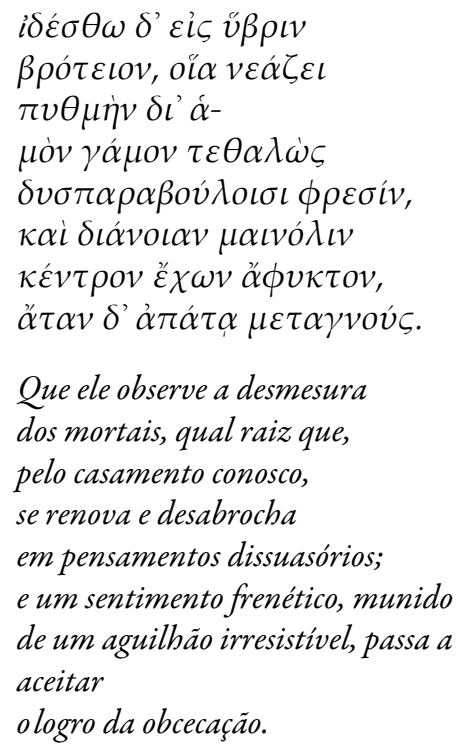

As palavras do coro de suplicantes apontam para um processo comum na tragédia esquiliana, ou seja, o resgate da aproximação que os poetas líricos fizeram entre à $\tau \eta$ ("obcecação", v. 110) e üßpis ("desmesura”, v. 104). No entanto, não se trata de uma união ao acaso, pois este é um tipo clássico de passagem em que a tradução dependerá muito do contexto em que os termos se inserem. Ao longo de toda a tragédia, o coro enfatizará que é necessário eliminar a ả $\delta \delta \tilde{\omega} \nu$ üßpıs (“a desmesura dos homens”, v. 525), no preciso momento 
em que $\ddot{\alpha} \tau \eta$ estará novamente presente no excerto. Dessa forma, traduzir $\ddot{\alpha} \tau \eta$ por “obcecação" é reafirmar o padrão que Ésquilo mantém de seus antecessores literários. Ao perder o comedimento diante das situações, o homem eventualmente está sujeito a uma cegueira da razão, motivo pelo qual não consegue frear seus atos até que ele próprio caia em si.

A ocorrência de $\phi \rho \eta \dot{\nu}$ ("espírito", v. 108) assegura a relação coerente com o conceito de $\ddot{\alpha} \tau \eta$, apontando para a sensibilidade das suplicantes e a intensidade dos sentimentos. $\mathrm{O}$ universo da tragédia em que as mulheres estão em destaque é nitidamente mais sensível que o masculino e, portanto, a relação com a palavra $\phi \rho \eta \dot{\nu}$, que por muitos momentos pode ser traduzida como "âmago", "alma", remete a um estágio de maior passionalidade. No entanto, a tragédia não apresenta apenas as paixões humanas, mas, também, enfoca a racionalidade e, para o coro, os Egiptíades não apenas são possuidores de $\delta v \sigma \pi \alpha p a \beta o \dot{\lambda} \lambda o$ เ เ

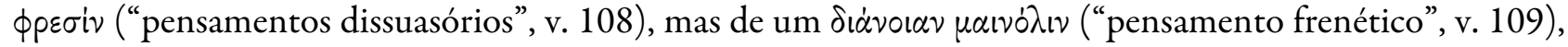
indicando que, por causa da úßpıs, estes homens não dominam nem as questões sentimentais nem as racionais; são portanto, propensos ao "logro da obcecação". Ademais, a própria üßpıs está ligada ao domínio dos desejos naturais, é uma "ausência de controle" dos próprios Egiptíades, carregados por seus instintos e que não mesuram suas ações diante das belas pretendidas.

Ao rogar o auxílio divino, o coro novamente associa a metáfora náutica com o conceito de $\ddot{\alpha} \tau \eta$ (vv. 523-530):

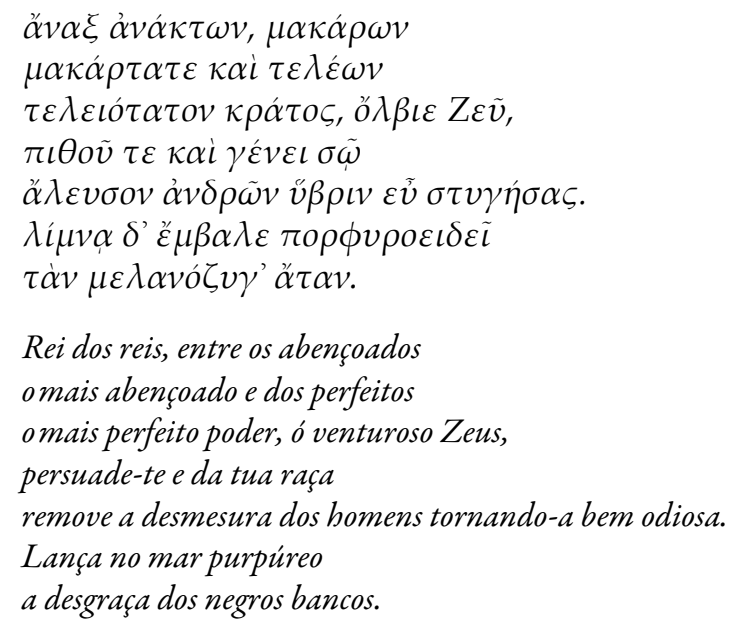

O tom litúrgico da passagem não pode ser menosprezado. Trata-se de uma verdadeira prece das Danaides para que Zeus puna seus algozes, que estão vindo para reivindicar o casamento. De acordo com as suplicantes, somente Zeus do alto de seu poder é quem pode lidar com a üßpı e castigar os Egiptíades. É interessante notar, primeiramente, a diferença de perspectiva entre Pelasgo e as suplicantes. O rei vê no mar a ameaça que chega às suas terras, o mesmo mar que, de certa forma, foi a salvação, mesmo que momentânea, das Danaides;

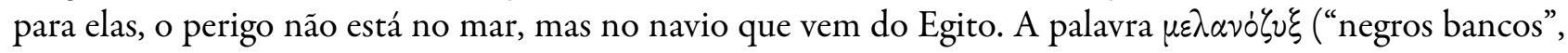
v. 530) reforça este aspecto. Trata-se de um termo com esta única ocorrência em toda a literatura grega e seu significado mais claro é, segundo Bailly (2000, p. 1242), uma referência aos bancos com remadores negros, ou seja, aos próprios egípcios.

Dessa forma, as suplicantes rogam a Zeus para que ele mande ao mar os egípcios e, portanto, a $\alpha \varkappa \eta$ "decadência" que vem na direção delas. A passagem coloca em concordância a ä $\tau$ e e a üßpıs, no entanto, define de forma clara o que pertence a cada um: a üßpı "desmesura” é o motivo que leva os Egiptíades ao encontro das Danaides e a ä $\tau \eta$ é o resultado dos males que eles vêm trazendo do Egito até estas mulheres.

É perceptível, desde o começo, que há um crescente na função do coro em orientar e advertir os homens sobre os efeitos das atitudes deles. Esse tipo de atitude, ora admoestativa ora preocupada e, acima de tudo, litúrgica, ganha uma função clara na Oresteia, de 458 a.C. Das três tragédias que compõem a trilogia, é Agamêmnon a principal peça em que o conceito de ả̃ é explorado em toda a sua plenitude, inclusive pelo 
próprio coro. Ésquilo experimenta o conceito de forma tão contundente que, posteriormente, em Sófocles e Eurípides, todas as nuanças discutidas refletem algo que já havia sido pensado, pelo menos de forma muito sutil, na primeira peça da Oresteia.

A tragédia possui quinze ocorrências do conceito $\ddot{\alpha} \tau \eta$; em comparação com as outras produções remanescentes do período clássico, trata-se de uma quantidade que extrapola uma média geral de ocorrências. E se, em termos estatísticos, não é mesmo assim a peça em que o conceito tem maior presença em relação ao total de palavras, ${ }^{7}$ é a tragédia da ä $\tau \eta$ por excelência. O mesmo herói, que foi o primeiro na tradição ocidental a ser tomado pela influência funesta da ä $\tau \eta$ na Ilíada, é, novamente, na tragédia, aquele que, diante dos olhos do espectador, sofrerá as consequências dessa mácula que os gregos conheciam tão bem através dos versos homéricos e da cosmogonia hesíodica.

A peça apresenta o conceito de $\ddot{\alpha} \tau \eta$ de uma forma tão ampla e relacionada de modo tão intrínseco com a família dos Atridas que, diferentemente da Ilíada, em poucos passos se faz menção direta aos atos de Agamêmnon e acabará por revelar um estigma que pertence à própria raça. Na procura de respostas para os presságios sobre a situação dos combatentes de Tróia e o que esperar da ação das divindades, o coro canta à glória de Zeus, no chamado "Hino a Zeus" (vv. 160-183), que se inicia com uma espécie de prece ritualística em que o próprio coro invoca os inúmeros nomes do senhor dos deuses e atesta para sua potência e onipresença. Há, além disso, uma interessante relação entre a fala do coro e a cosmogonia hesíodica; ao

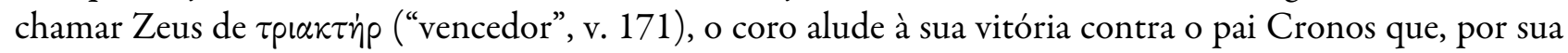
vez, havia destronado Urano. Tais passagens, presentes na Teogonia (154-210, 453-506), de acordo com Athanassakis (2004, p. 47), mostram duas entidades que foram sacrificadas por mulheres em favor de um novo reinado. Logo, é possível pensar que a alusão às origens de Zeus não seja tão gratuita, mas façam também uma referência ao próprio Agamêmnon, detentor do poder de Argos e que, em breve, seria um governante caído diante do poder de uma mulher.

As palavras do coro lembram que o poder supremo de Zeus é o responsável pelo controle da imperfeição humana e pela aprendizagem que lhe é imposta (v. 174-175). Através das palavras dos cidadãos, é dita uma lição que marca de forma crucial toda a Oresteia, pois o $\pi \dot{\alpha} \theta \varepsilon \iota \mu \dot{\alpha} \theta \circ \varsigma$ ("aprendizado pelo sofrimento", v. 177) ecoará por toda a trilogia e é uma das chaves essenciais para a compreensão de toda a saga dos Atridas.

Ao dizer que o "aprendizado pelo sofrimento" é a forma pela qual o homem reconhece a prudência, mesmo que $\alpha^{\prime} \dot{\varepsilon} \kappa \omega \nu$ ("a contragosto", v. 181), o coro revela, também, a proximidade entre o conceito de $\alpha^{\prime} \tau \eta$, uma influência maligna, que afeta a família há gerações, e o $\pi \dot{\alpha} \theta \varepsilon \iota \mu \dot{\alpha} \theta \circ \varsigma$, "o aprendizado pelo sofrimento". Conforme deixa claro Lloyd-Jones (1983, p. 87), as lições transmitidas por Ésquilo em Agamêmnon evidenciam que o $\pi \dot{\alpha} \theta \varepsilon \iota \mu \dot{\alpha} \theta \circ \varsigma$ não está necessariamente relacionado ao próprio autor do ato, mas seria uma espécie de "lição" universal da justiça divina como prova de que, em algum momento, algum membro de uma família envolvida em uma transgressão poderia sofrer as consequências. Dessa forma, corroborando Lloyd-Jones, Doyle (1984, p. 95) tece uma interessante reflexão: de um sentido que já aponta para um distanciamento da ideia primordial de influência maligna, que se estabelece apenas sobre um único indivíduo, a $\ddot{\alpha} \tau \eta$ acaba por se configurar de forma bastante contundente como uma espécie de $\pi \dot{\alpha} \theta \varepsilon ı$ $\mu \dot{\alpha} \theta$ os; ou seja, a "desgraça" familiar é o processo de aprendizagem pelo qual os membros desta raça precisam passar para compreender que os erros, necessariamente, pedem reparação e que o conhecimento só se consegue pela dor.

É nesse ponto que, se Zeus é soberano, o $\pi \dot{\alpha} \theta \varepsilon \iota \mu \dot{\alpha} \theta_{\circ}$ s recai, em algum momento, sobre a própria pessoa ou sobre os outros membros do clã; no exercício de seu poder, Zeus é, como constata Lloyd-Jones (1983, p. 87), desde Hesíodo, em Trabalhos e Dias é aquele que tem a $\Delta$ ikn (“Justiça”, v. 259) sentada ao seu lado e, portanto, está sempre atento aos momentos em que a filha o lembrará de punir o culpado ou seus descendentes.

Há duas passagens em Agamêmnon que merecem atenção. A primeira ocorrência de ä $\tau \eta$, por intermédio do coro de cidadãos, acontece no verso 361 (vv. 355-361):

$\tilde{\omega} Z \varepsilon \tilde{v} \beta \alpha \sigma \iota \lambda \varepsilon \tilde{v} \kappa \alpha i \operatorname{Nv} \xi \phi \iota \lambda i ́ \alpha$

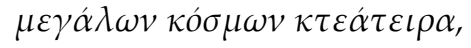




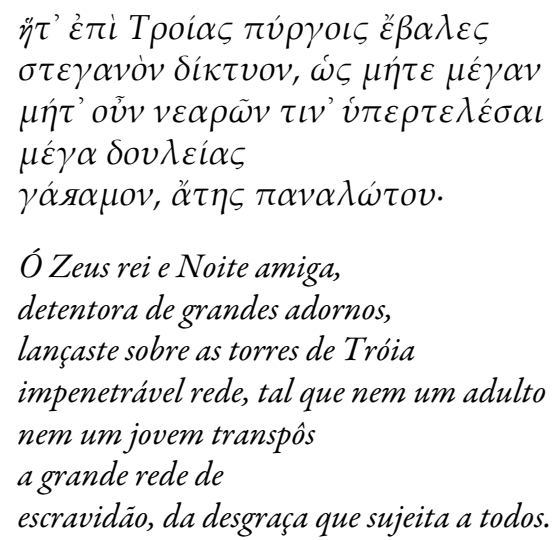

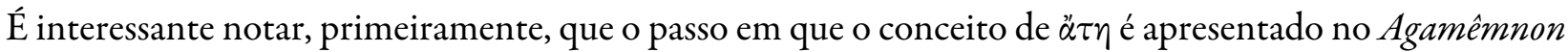
diz muito sobre a tradição literária que influenciou Ésquilo. Em perfeita consonância com a forma que o

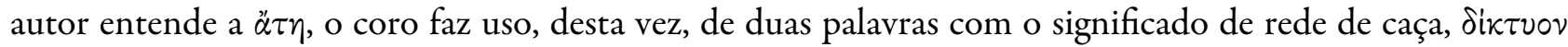

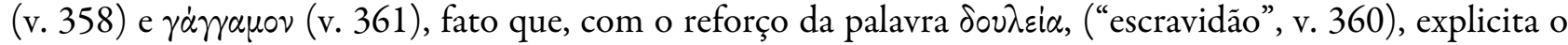
significado que a rede possui para o contexto de $\alpha \tilde{\tau} \eta$. Não se trata pura e simplesmente do uso de uma rede por causa de seu poder de imobilização, mas a imagem criada por Ésquilo vai além, aliando a rede ao fato de o homem se tornar subjugado, o que reforça uma impotência diante da influência maligna da $\ddot{\alpha} \tau \eta$.

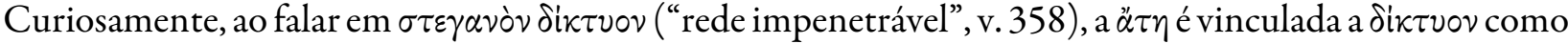
um reforço da incapacidade do homem de escapar diante da "desgraça" que o aguarda. É exatamente este o motivo pelo qual o uso metafórico de uma "rede de escravidão" (vv. 360-361) faz-se de extrema importância, pois o conceito de ä $\tau \eta$ terá o sentido de uma "desgraça”. Dessa forma, não se trata de uma "obcecação", uma rede que prende o homem e obscurece seus pensamentos, mas de uma rede que o manipula de tal forma a transformar seus atos, mesmo que o herói tenha ciência deles, em derradeira "desgraça". Ainda que o ser humano não escape a um destino de infortúnio ou às forças que comandam a ordem universal, não deixa, mesmo assim, de deter um espaço de liberdade de escolha e, com ela, de responsabilidade.

Uma questão pertinente que se insere na análise do passo é o uso do conceito de ä $\tau \eta$ com letra minúscula em um consenso não discutido pelos editores. Embora não haja nenhuma edição de Agamêmnon em que o conceito de $\ddot{\alpha} \tau \eta$, para este verso, seja apresentado com letra maiúscula, comentadores como Green (1943, p. 25) acabam por traduzir $\ddot{\alpha} \tau \eta$ como uma divindade, ou seja, a referenciam com letra maiúscula. Mesmo que o autor não comente tal uso, é perceptível o porquê da presença da figuração divina; o próprio adjetivo $\pi \alpha \nu \dot{\alpha} \lambda \omega \tau$ เ ("que sujeita a todos", v. 361) parece referenciar uma força maligna que é mais do que apenas abstrata, mas que, de fato, envolve em sua trama, enquanto personificação de um poder maior exercido sobre o ser humano.

No início da passagem, o coro de cidadãos responsabiliza Zeus e a Noite por lançarem uma rede sobre as torres de Tróia que, inclusive, atingiu os gregos. Trata-se de uma referência aos percalços também enfrentados pelas tropas helenas durante a tomada da cidade. Zeus é o detentor da justiça divina e figura que raramente

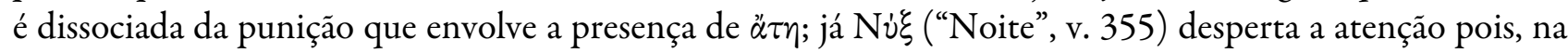

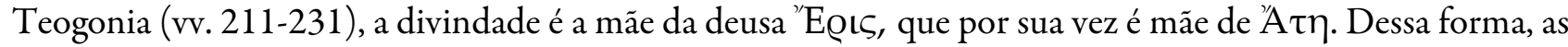
duas entidades responsabilizadas, justamente, são invocadas como detentoras de um poder superior que os próprios deuses lançaram aos homens.

Logo nos versos seguintes, uma nova menção ao termo dá indicações de que a importância de $\ddot{\alpha} \tau \eta$ para Ésquilo em Agamêmnon obriga o autor, inclusive, agora de forma mais enfática, a reinventar uma cosmogonia. Trata-se do momento em que o coro irá justificar a justiça divina que se recai sobre os homens que excedem, tanto em riquezas quanto em suas próprias ações (vv. 372-386): 


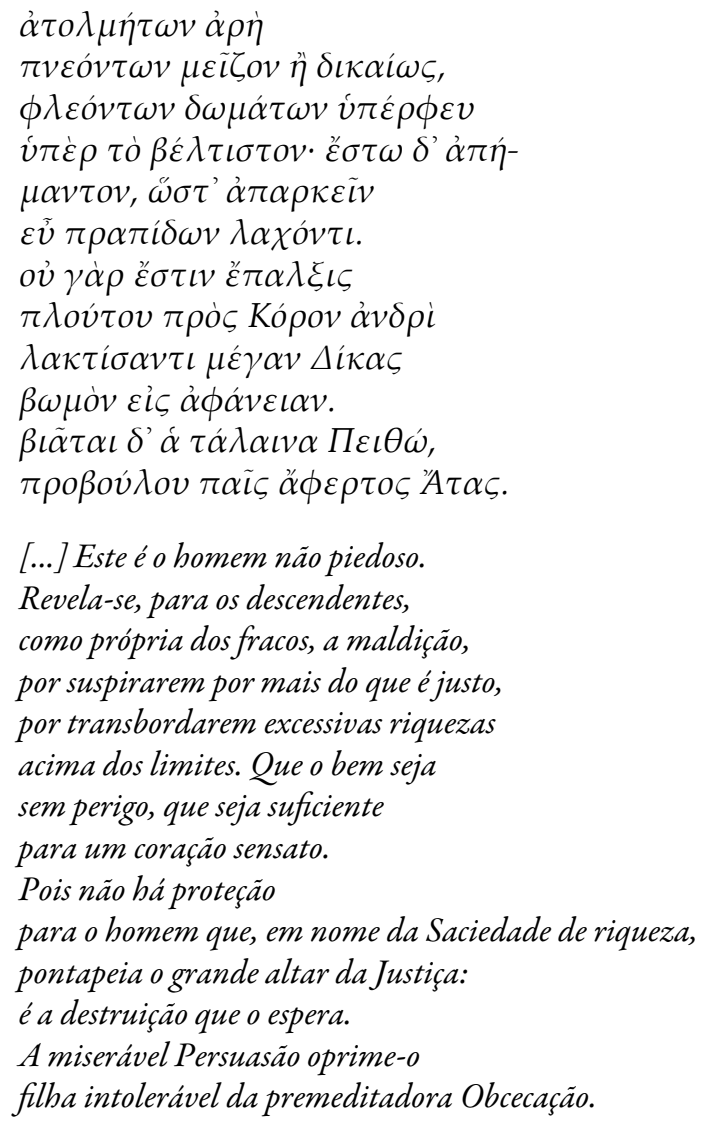

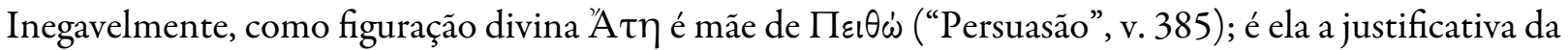
falta de Kópos, "saciedade", (v. 381) de Páris, ao pensar em um caso específico, ao raptar Helena e, assim, levar aos troianos toda a desgraça da guerra. No entanto, a $\ddot{\alpha} \tau \eta$ referencia mais do que apenas Páris e o próprio Agamêmnon, visto que a questão da justa medida dialoga de forma contundente com as palavras de Clitemnestra, de alcance mais universal sobretudo quando se trata do ambiente de uma campanha e seus objetivos (vv. 340-341). Logo, se para Ésquilo a å $\tau \eta$ é a catástrofe que se abateu sobre os troianos, aliá-la à

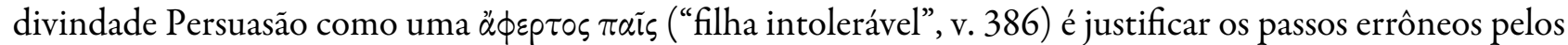
quais o homem passa ao longo de sua vida; mas, mais do que isso, é reforçar um aspecto contundente da tragédia de Agamêmnon, muito bem pontuado por Doyle (1984, p. 88):

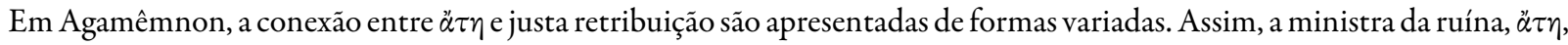
que traz destruição, $\ddot{\alpha} \tau \eta$, para a casa que ele nutria é dada uma característica nobre: ela é divinamente enviada. A destruição de Tróia, naturalmente para um grego, é celebrada como o trabalho de Zeus pelo coro e por Agamêmnon em seu retorno.

Sendo assim, a à $\tau \eta$ é um aspecto central de todos os atos responsáveis pelos acontecimentos presentes, e não é de estranhar que Ésquilo aproxime entidades que os justifiquem e, de forma extremamente natural, esclareçam o percurso e atitudes dos heróis, quer da parte dos vencedores, quer dos vencidos. Dois adjetivos

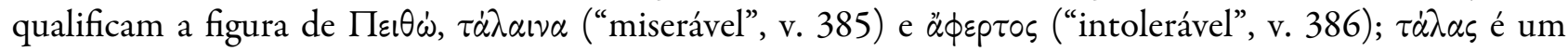
adjetivo recorrente nos contextos em que $\ddot{\alpha} \tau \eta$ é apresentada e está ligado àqueles que sofrem pela intervenção

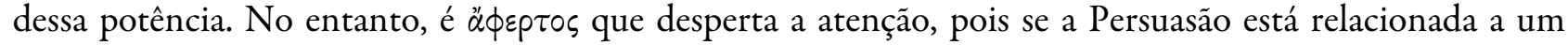
convencimento, uma "intolerável Persuasão" reforça a influência de uma convicção errônea do homem, justamente a atitude de Páris em levar da Grécia a bela Helena, como a de Agamêmnon em arrasar os templos dos deuses e em cometer genocídio em nome da ambição.

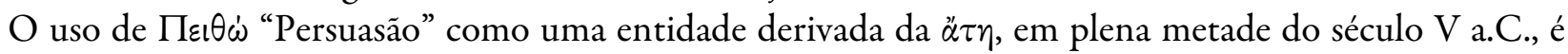
um aspecto que vale menção. Nesta mesma época, em Atenas, há uma efervescência das teorias retóricas 
e é Córax, em 465 a.C., que definirá a arte retórica como "criadora da Persuasão". ${ }^{8}$ No princípio, como afirma Reboul (2004, p. 6), a arte retórica era vista com suspeita pelos gregos, principalmente porque o ato de persuadir alguém pela palavra sugeria um domínio perigoso sobre o outro indivíduo; só posteriormente, com a ida de Górgias para Atenas, é que os atenienses passaram a observá-la como uma técnica, sedutora para os ouvidos, mas de critérios éticos muito duvidosos; a verdade, manipulada pela retórica, perde diante do poder da Persuasão.

Deste modo, a "Persuasão" aliada à $\alpha \tau \eta$, no passo, explora justamente um juízo de valores que não é visto como um uso íntegro e justo da palavra, mas que auxilia o homem a interpretar o mundo de acordo com suas próprias necessidades e interesses. A palavra que qualifica a deusa 'A $\tau \eta$ é $\pi p o ́ \beta o v \lambda \circ \varsigma$ ("premeditadora", v. 386); sendo assim, a $\alpha$ $\tau \eta$ é "a desgraça que premedita” e, sua filha, a "intolerável Persuasão", só pode ser aquela que, por meio de argumentos falhos devido à desgraçada premeditação da $\alpha$ $\tau \eta$, induz o homem ao erro. No entanto, é inegável que uma nova forma de pensar o mundo, em voga na Atenas do século V a.C., propicia um raciocínio mais complexo e amplo em relação ao universo em que se inserem homens e deuses.

Coéforas, parte central da trilogia composta pelas tragédias Agamêmnon e Eumênides, foi apresentada em 458 a.C., ganhando o primeiro prêmio. Trata-se de uma tragédia que enfoca o retorno de Orestes do exílio e o cumprimento das ordens de Apolo para que Orestes vingasse a morte de Agamêmnon. É na décima segunda ocorrência do conceito de ä $\tau \eta$ em Coéforas, apesar de ele ser apresentado por meio do coro de libadoras por diversas vezes, que o sentido de advertência apresentado até o momento, de um coro que anuncia a desgraça que se aproxima, ganha um contorno premonitório (vv. 965-968):

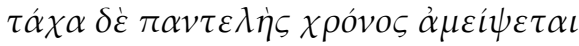

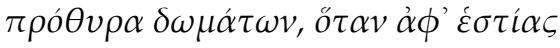

$\mu \hat{v} \sigma o \varsigma \alpha \check{\pi} \alpha \alpha \dot{\varepsilon} \lambda \alpha \theta \tilde{\eta} \iota$

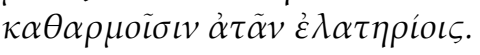

Rapidamente a hora decisiva vai penetrar a fachada do palácio, quando do núcleo familiar for expulsa completamente a abominação pelas purificaçôes que afastam os enganos.

O coro claramente faz uma referência aos diversos acontecimentos que, por muito tempo, maculam a casa dos Atridas, e $\dot{\varepsilon} \sigma \tau i \alpha$ ("núcleo familiar”, v. 966) reforça tal alusão. Entretanto, é a palavra $\mu \nu$ $\sigma \circ \varsigma$ ("abominação", v. 967) que está diretamente ligada às ã $\tau \alpha$ ( “enganos”, v. 968), traduzida dessa forma justamente por se tratar

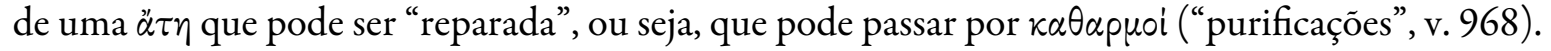

O passo, marcado pelas palavras que apontam para o ritual de sacrifício, rememora o estigma da família de Agamêmnon; a palavra $\mu \dot{\sigma} \sigma o \zeta$, segundo Chantraîne (2009, p. 725), envolve sobretudo a mácula do crime, do sacrilégio; juntamente com os vocábulos $\dot{\sigma} \tau i \alpha$ ("núcleo familiar") e $k \alpha \theta$ ppuoi ("purificações") reforça os diversos acontecimentos familiares que exigem o sacrifício: o banquete com os filhos de Tiestes, o destino de Ifigênia, o martírio de Agamêmnon e, agora, a própria morte de Clitemnestra e Egisto.

A última ocorrência de $\ddot{\alpha} \tau \eta$ a que esse trabalho se propõe a analisar pertence a uma das duas presenças do conceito em Eumênides (458 a.C.), parte final da trilogia denominada Oresteia. Já transformadas em Eumênides "Benfazejas" pelo conselho da deusa Atena, após o julgamento de Orestes, as entidades cantam a ¿ँ $\tau$, voltadas à retaliação, mas agora priorizando o bem comunitário (vv. 976-987):

$\tau \dot{\alpha} v \delta^{\prime} \ddot{\alpha} \pi \lambda \eta \sigma \tau o v \kappa \alpha \kappa \tilde{\omega} v$

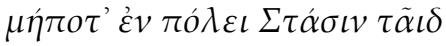

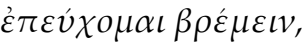

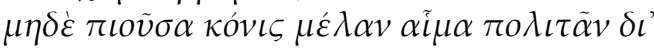

o $\rho \gamma \dot{\alpha} v \pi o \iota v \tilde{\alpha} \varsigma$

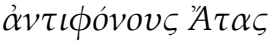

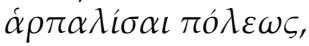




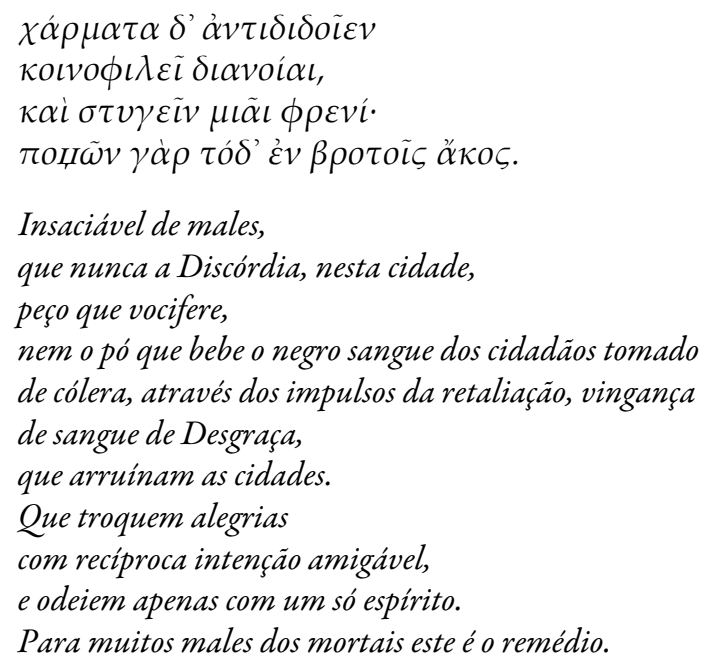

O canto das Eumênides (v. 978) informa através do verbo ė $\pi \varepsilon \dot{\chi} \chi 0 \mu \alpha \mathrm{l}$ ("orar”) que velará pela cidade contra qualquer situação que vá contra a ordem. A tradução de 'A implica a aceitação de todo o contexto, não só de Eumênides, mas de toda a trilogia. No verso 986 aparece $\phi \rho \eta \dot{v}$, como o local em que o homem precisa ser cauteloso dentro de si próprio para que não seja acometido pela $\ddot{\alpha} \tau \eta$, o que aproxima os dois conceitos, ainda que se trate de uma passagem em que $\ddot{\alpha} \tau \eta$ necessariamente tem um sentido objetivo, como implicação desastrosa da ação das Erínias.

A palavra $\chi \dot{\alpha} p \mu \alpha \tau \alpha$ ("prazeres", v. 983) é oposta no passo ao sentido dos males que a cidade possa sofrer,

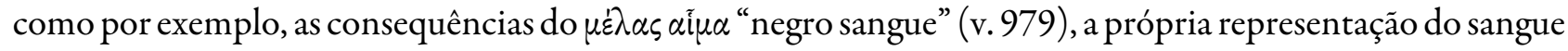
coagulado, rastro deixado por aquele que comete um crime. A presença de $\alpha^{\prime} \tau \eta$ atrelada a $\alpha^{\tau} \tilde{f} \mu \alpha$ ("sangue") e palavras derivadas é uma constante em toda a tragédia grega, no entanto, torna-se muito evidente na Oresteia. Para Goheen (1955, p. 113), por exemplo, certas imagens presentes na trilogia esquiliana transformam-se em "coisas" e representam ideias, atitudes e pensamentos.

\section{Conclús̃̃o}

Em Eumênides, por exemplo, é o próprio coro a personagem principal da ação. São as Erínias, posteriormente reconhecidas como benfazejas, que ditarão o andamento de toda a ação, pois são as responsáveis determinantes para a conclusão de toda a trama que envolve a família dos Atridas. Embora o coro já tivesse aparecido como personagem principal, como ocorre em Suplicantes, o próprio caráter das personagens, vítimas, acuadas, atormentadas pela figura dos Egiptíades, impossibilita o dinamismo que o coro recebe na tragédia final da trilogia Oresteia.

Dessa forma, percebe-se que de Persas a Eumênides o coro vai assumindo um papel de liderança cada vez maior e mais significativo para o desenrolar da trama. Se por um lado, o coro de anciãos em Persas apresenta uma postura mais distante, dando destaque aos personagens principais e figurando apenas como conselheiros, em tragédias como Coéforas, em que as libadoras cumprem um papel de conselheiras de Electra, não é possível definir a presença delas apenas como uma alegoria do espectador, mas elas são um personagem vivo, eloquente e expressivo da ação dramática que definem, inclusive, a atitude da filha de Agamêmnon. Não é para menos que, em Coéforas, o uso do conceito de ä $\tau \eta$ é o tempo todo realçado de forma incisiva e se torna o veículo condutor da necessidade de ação de Orestes, o que explica o motivo pelo qual o próprio drama encerra-se com a palavra $\ddot{\alpha} \tau \eta$ (v. 1076).

Esse crescente na importância dada ao coro é perfeitamente justificável com as ocorrências do conceito de $\ddot{\alpha} \tau \eta$, pois à medida que ganha destaque no drama, o coro passa a reproduzir os elementos sociais, culturais, políticos e religiosos, fazendo deles o suporte das discussões que eram próprias da cidade cosmopolita 
que Atenas representava ao longo do século $\mathrm{V}$ a.C. Sendo assim, o título do trabalho procura evidenciar justamente esse papel de anunciadores que o coro apresenta em todos os dramas. Independentemente de seu papel de conselheiro, orientador, admoestador ou mesmo acusador, a presença do conceito de $\ddot{\alpha} \tau \eta$ com maior ênfase nas partes líricas da tragédia denunciam a preocupação constante de um povo com os elementos que lhes eram caros para um justo equilíbrio entre os atos humanos e as reparações necessárias que, no caso de Ésquilo, necessariamente, resultam da ação direta das divindades.

\section{REFERENCIAS}

Bailly, A. (2000). Le grand Bailly: Dictionnaire grec-français. Paris: Hachette.

Cameron, H. D. (1971). Studies on the "Seven against Thebes" of Aeschylus. Paris: Mouton.

Chantraîne, P. (2009). Dictionnaire étymologique de la langue grecque. Paris: Klincksieck.

Dale, A. M. (1969). Collected papers. Cambridge: University Press.

Dodds, E. R. (1953). The Greeks and the irrational. California: University Press.

Doyle, R. E. (1984). ATH: its use and meaning. A study in the greek poetic tradition from Homer to Euripides. New York: Fordham University Press.

Ewans, M. (2018). Aeschylus and Opera. En K. N. Demetriou (Ed.), Brill's companions to classical reception (pp. 205-224). Leiden: Brill.

Goheen, R. F. (1955). Aspects of Dramatic Symbolism: Three Studies in the Oresteia. The American Journal of Philology $76(2), 113-137$.

Grimal, P. (1993). Dicionário da mitologia grega e romana (2 ed.). Rio de Janeiro: Bertrand Brasil.

Kitto, H. D. F. (2011). Greek tragedy (7 ed.). New York: Routledge.

Ley, G. (2007). The theatricality of Greek tragedy; playing space and chorus. Chicago: University Press.

Liddell, H. G. y Scott, R. (1996). A Greek-English Lexicon. Oxford: Clarendon.

Lloyd-Jones, H. (1983). The justice of Zeus (2 ed.). California: University Press.

Moreau, A. (1986). Eschyle: la violence et le chaos. Paris: Les Belles Lettres.

Roisman, H. (1983). Hesiod's "A $\tau$. Hermes, 111 (4), 491-496. Recuperado de http://www.jstor.org/stable/4476340

Saï, S. (1976). La faute tragique. Paris: François Maspero.

Sommerstein, A. H. (2002). Greek drama and dramatists. London: Routledge.

Swift, L. A. (2010). The hidden chorus: echoes of genre in tragic lyric. Oxford: University Press.

Thalmann, W. G. (1978). The dramatic art in Aeschylus' Seven against Thebes. New Haven and London: Yale University Press.

Vernant, J-P. y Vidal-Naquet, P. (2008). Mito e tragédia na Grécia antiga. São Paulo: Perspectiva.

Vickers, B. (1973). Towards greek tragedy: drama, myth, society. London: Longman.

\section{EDIÇÕES E COMENTÁRIOS}

Athanassakis, A. N. (Ed.). (2004). Hesiod: Theogony, Works and Days, Shield (2 ed.). Baltimore: The John Hopkins University Press.

Diggle, J. (Ed.). (1984). Euripides Fabulae. Tomus I: Cyclops, Alcestis, Medea, Heraclidae, Hippolytus, Andromacha, Hecuba. New York: University Press.

Mazon, P. (Ed.). (1967). Homère: Iliade. Tome IV: chants XIX-XXIV (16 ed.). Paris: Les Belles Lettres.

Page, D. (Ed.). (1972). Aeschyli septem quae supersunt tragoedias. New York: Oxford University Press. 


\section{Notas}

1 A esse respeito, vide: Pelling, C. (2001). Greek Tragedy and the Historian. Oxford: Clarendon Press.

2 O conceito de $\ddot{\alpha} \tau \eta$ não possui nenhuma ocorrência nas comédias de Aristófanes.

3 As traduções de todos os textos presentes no artigo, incluindo as versões do grego clássico, são de minha autoria.

4 As ocorrências nas tragédias e no coro do conceito de ä $\tau \eta$ em Ésquilo apresentam-se da seguinte forma: Persas (472 a.C.), 5 ocorrências (3 no coro); Sete Contra Tebas (467 a.C.), 5 ocorrências (3 no coro); Suplicantes (463 a.C.), 5 ocorrências (2 no coro); Agamêmnon (458 a.C.), 15 ocorrências (7 no coro); Coéforas (458 a.C.), 13 ocorrências (10 no coro) e Eumênides (458 a.C.), 2 ocorrências (2 no coro). Em Prometeu Acorrentado (462-459, 452-420) o conceito aparece 3 vezes, mas em nenhuma delas por meio do coro das Oceânides.

5 A data de 467 a.C. para Sete contra Tebas é consensual entre os estudiosos. Tanto Sommerstein (2002, p. 34) quanto Page (1972, p. 44) apresentam a mesma datação para a obra.

6 A primeira versão do livro de Kitto, Greek Tragedy, de 1929, propunha a data de 492 a.C. como provável para a representação da peça, pois se acreditava que Suplicantes era a mais antiga das tragédias preservadas. No entanto, na edição de 1961, Kitto, perante novos elementos de informação, acrescenta uma nova interpretação para a peça e restabelece sua data como sendo por volta de 464 a.C. Este fato deve-se ao papiro de Oxirrinco (2256 fr. 3), publicado em 1952, e que apontava a vitória de Ésquilo com a tragédia, durante o exercício do arconte Arquidêmides, entre os anos de 464 e 463 a.C. Sommerstein (2002, p. 89) não se compromete com um ano específico, apenas aponta que a peça teria sido escrita por volta de 460 a.C. A edição de Oxford (1972) prefere o ano de 463 a.C.

7 Em termos estatísticos, a ocorrência de ä $\uparrow \eta$ em Coéforas é mais significativa que em Agamêmnon, visto que o número de versos das duas tragédias diferem consideravelmente, mas a quantidade de ocorrências do vocábulo ä $\tau \eta$ é praticamente o mesmo.

8 A esse respeito, vide: Verrall, A. W. (1880). Korax and Tisias. Journal of Philology 9 (10), 197-210. Wilcox, S. (1942). The Scope of Early Rhetorical Instruction. Harvard Studies in Classical Philology 53, 121-155. Kennedy, G. A. (1963). The Art of Persuasion in Greece. Princeton: University Press. Worthington, I. (2007). A Companion to Greek Rhetoric. Oxford: Blackwell Publishing. 